\title{
Prescription of opioid analgesics and related harms in Australia
}

\section{Amanda Roxburgh \\ MCrim, MPsych(Clin) MAPS, Senior Researcher \\ Raimondo Bruno BSc(Hons), PhD, MAPS, Senior Lecturer ${ }^{2}$ \\ Briony Larance BSc(Psych)(Hons), Senio Researcher \\ Lucy Burns MPH, GradDipHealthPolicy $\mathrm{PhD}$, Senior Lecturer \\ 1 National Drug and Alcoho Research Centre, Universit of New South Wales, Sydney, NSW. \\ 2 School of Psychology, University of Tasmania Hobart, TAS \\ a.roxburgh@unsw.edu.au}

MJA 2011; 195: 280-284 doi: 10.5694/mjal0.11450

Editorial p 248 Letter p 264
T here has been growing concern among Australian medical professionals about the increase in prescribing of opioid analgesic preparations (particularly morphine and oxycodone) over the past decade. Australia's consumption of opioid analgesics is ranked 10th internationally; North America ranks first. Per capita consumption of oxycodone and morphine preparations in Australia is relatively high (ranked third and fifth respectively, internationally); Canada ranks first for oxycodone and Austria first for morphine. ${ }^{1}$ Consumption levels in Australia are still well below the topranking countries. Previous research in Australia has documented increases in the number of prescriptions for morphine in the late $1990 \mathrm{~s}^{2,3}$ and, more recently, increases in consumption of oxycodone. ${ }^{4}$

Morphine and oxycodone have legitimate and important treatment indications in the management of pain. Access to effective pain management is an important human right, and pain, both acute and chronic, imposes a major public health burden internationally. ${ }^{5}$ Morphine (and codeine) are listed by the World Health Organization as drugs of choice for treating chronic and severe cancer pain. 6 Opioid analgesics are also widely used for pain not related to cancer. ${ }^{7}$ However, there are as yet no overarching international guidelines about prescribing these drugs in broader pain management presentations. $^{8}$

One of the chief concerns about the increased availability of opioid medications is the potential for a concomitant increase in non-medical use (in this article, this term refers to use of substances without prescription) and diversion (buying, selling or passing on drugs, outside of prescribed use). Non-medical use and diversion are complex behaviours, and may occur among different groups of consumers, including patients with chronic nonmalignant pain, patients with cancer pain and illicit drug users. 7,9

\section{Abstract}

Objective: To document trends in: (i) prescribing of morphine and oxycodone; (ii) hospital separations for overdose; (iii) presentations for treatment of problems associated with these drugs; and (iv) oxycodone-related mortality data in Australia.

Design and setting: Cross-sectional study analysing prescriptions for morphine and oxycodone based on figures adjusted using Australian Bureau of Statistics estimated resident population and prospectively collected data from: (i) the National Hospital Morbidity Database on hospital separations primarily attributed to poisoning with opioids other than heroin ("other opioids"); (ii) the Alcohol and Other Drug Treatment National Minimum Data Set for treatment episodes where morphine or oxycodone were the primary or other drugs of concern; (iii) the National Coronial Information System on deaths where oxycodone was the underlying cause of death or a contributory factor.

Main outcome measures: Population-adjusted numbers of (i) prescriptions for morphine and oxycodone by 10-year age group, (ii) hospital separations for "other opioid" poisoning, and (iii) treatment episodes related to morphine or oxycodone; and (iv) number of oxycodone-related deaths.

Results: Prescriptions for morphine declined, while those for oxycodone increased. Prescriptions for both were highest among older Australians. Hospital separations for "other opioid" poisoning doubled between the financial years 2005-06 and 2006-07. Treatment episodes for morphine remained stable, while those for oxycodone increased. There were 465 oxycodone-related deaths recorded during 2001-2009.

Conclusions: Oxycodone prescriptions in Australia have increased, particularly among older Australians. The increase may, in part, reflect appropriate prescribing for pain among an ageing population. However we are unable to differentiate non-medical use from appropriate prescribing from this data. In comparison to heroin, the morbidity and mortality associated with oxycodone is relatively low in Australia. There is a continued need for comprehensive training of general practitioners in assessing patients with chronic non-malignant pain and prescribing of opioids for these patients, to minimise the potential for harms associated with use of these medications.

There is clear evidence of the harms related to non-medical use of prescription opioids, including overdose, injection-related harms and dependence. ${ }^{10}$ Data from the United States Food and Drug Administration Adverse Event Reporting System shows that oxycodone contributed to the largest number (5548) of all drugrelated deaths in North America during the period 1998 to 2005 (morphine ranked fourth, contributing to 1616 deaths). ${ }^{11}$ In another study investigating North American accidental pharmaceutical overdose deaths, non-medical use of pharmaceuticals was involved in $63 \%$. Doctor shopping (where five or more health professionals were consulted) was evident in $21 \%$ of deaths. ${ }^{12}$

In this article, we provide an update to trends in prescribing opioid analgesics, focusing particularly on morphine and oxycodone, given that these are the predominant products on the market. We also present data on presentations for treatment for problems related to oxycodone and morphine, and hospital presentations for opioid overdose (excluding heroin). Finally, for the first time in Australia, we present an analysis of oxycodone-related mortality at a national level.

\section{Methods}

\section{Prescription data}

Morphine and oxycodone prescription data (2002-2008) were obtained from the Drug Utilisation Sub-Committee of the Pharmaceutical Benefits Advisory Committee.

Numbers of morphine prescriptions for oral preparations, by year, were collected for: $10 \mathrm{mg}, 20 \mathrm{mg}$ and $30 \mathrm{mg}$ immediate-release tablets; 
$5 \mathrm{mg}, 10 \mathrm{mg}, 15 \mathrm{mg}, 30 \mathrm{mg}, 60 \mathrm{mg}$, $100 \mathrm{mg}$ and $200 \mathrm{mg}$ controlled-release tablets; $30 \mathrm{mg}, 60 \mathrm{mg}$, $90 \mathrm{mg}$ and $120 \mathrm{mg}$ controlled-release capsules; and $10 \mathrm{mg}$, $20 \mathrm{mg}$, $50 \mathrm{mg}$ and $100 \mathrm{mg}$ sustained-release capsules. Numbers of oxycodone prescriptions for oral preparations, by year, were collected for: $5 \mathrm{mg}$ tablets; $10 \mathrm{mg}$, $20 \mathrm{mg}$, $40 \mathrm{mg}$ and $80 \mathrm{mg}$ controlled-release tablets; and $5 \mathrm{mg}, 10 \mathrm{mg}$ and $20 \mathrm{mg}$ capsules. Results are presented per 1000 population, by 10-year age group.

\section{Hospital separations}

We present data from the National Hospital Morbidity Database (NHMD) for the financial years 1999 00 to 2007-08. These are coded according to the International classification of diseases and related health problems, 10th revision, clinical modification (ICD-10-CM). ${ }^{13}$ We present hospital separations where the principal diagnosis was "other opioid" poisoning; this poisoning code includes morphine, oxycodone and codeine.

\section{Treatment presentations}

We present data from the Alcohol and Other Drug Treatment Services National Minimum Data Set (AODTS-NMDS) for the financial years 2002-03 to 2007-08. Data represent the number of treatment episodes where morphine or oxycodone was the primary drug, or other drug, of concern, and relate to closed treatment episodes (which means some episodes may be excluded if the patient did not finish treatment within the given time frame).

\section{Deaths}

It is difficult to distinguish between deaths from heroin and from morphine because of the way that heroin is metabolised. ${ }^{14}$ It is likely that many deaths recorded as morphine-related deaths may be heroin-related. Accordingly, we examined only oxycodonerelated deaths. The National Coronial Information System (NCIS) was searched for deaths where oxycodone toxicity or overdose was recorded as a direct or contributory cause of death (2001-2009), and where oxycodone was found at fatal levels in the blood. Only closed cases, where the final cause of death had been determined by the coroner, were included.
The NCIS contains coronial files from all states and territories in Australia. Searches were conducted using the category "pharmaceutical substance for human use", and either leaving the descriptor field for these substances blank or specifying the subcategory as "analgesic, antipyretic, antirheumatic", and further specifying "oxycodone". Free text searches were also conducted on findings documents, which yielded some extra cases. Only deaths where oxycodone was mentioned were included in analyses.

We present numbers of oxycodone deaths, and adjusted numbers of oxycodone deaths per million defined daily doses of oral oxycodone preparations prescribed in that year. ${ }^{15}$

\section{Data analysis}

Analyses were conducted using PASW Statistics version 18.0 (SPSS Inc, Chicago, Ill, USA). Numbers of prescriptions per 1000 population were calculated using the Australian Bureau of Statistics (ABS) estimates of the population as at 30 June for each corresponding year. Trends in changes over time in prescriptions and dose formulations were analysed using ordinary least squares linear regression; all trends (except where noted) were strongly linear and, in all cases, findings concurred with non-parametric (Spearman) correlation techniques. Differences between injecting drug users (IDUs) and non-IDU decedents were analysed using $t$ test, odds ratio and $\chi^{2}$ analyses.

\section{Ethics approval}

This study was approved by the Human Research Ethics Committees of the University of New South Wales, and the Victorian Department of Justice.

\section{Results}

\section{Prescription trends in Australia}

Morphine prescriptions declined from 38.3 to 30.7 per 1000 population between 2002-03 and 2007-08, representing a decrease of about $20 \%$. Box $1 \mathrm{~A}$ shows trends in morphine prescriptions by 10 -year age group. Prescriptions were most common among older people (aged 70-79 and 80+ years), and much less common among younger people (aged 20-29 and 30-39 years). Significant linear declines over time were apparent in all age groups except the 50-59-year group. Linear regression showed statistically significant annual declines in morphine prescriptions per 1000 population for all age groups (except the 50-59-years group) of: 20-29 years, 0.78 (95\% CI, 0.73-0.82; $P<0.001$ ); 30-39 years, 2.11 (95\% CI, 1.81-2.41; $P<0.001)$; $40-49$ years, 1.21 (95\% CI, $0.59-1.83 ; P=0.02$ ); 50-59 years (no change; $P=0.44) ; 60-69$ years, 1.99 (95\% CI, 1.68-2.31; $P<0.001) ; 70-79$ years, 5.39 (95\% CI, 3.96-6.82;

\section{Prescriptions for morphine* and oxycodone ${ }^{\dagger}$ dispensed on the Pharmaceutical Benefits Scheme in Australia from 2002 to 2008 , per thousand population, by 10 -year age group ${ }^{\ddagger}$}

\section{(A) Morphine}

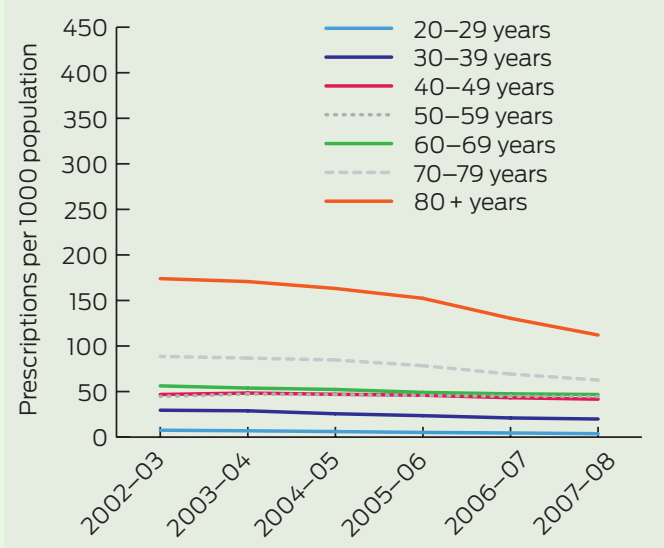

* Includes 10 mg, 20 mg and 30 mg immediate-release tablets; 5 mg, 10 mg, 15 mg, 30 mg, 60 mg, 100 mg and 200 mg controlledrelease tablets; $30 \mathrm{mg}, 60 \mathrm{mg}, 90 \mathrm{mg}$ and $120 \mathrm{mg}$ controlled-release capsules; and $10 \mathrm{mg}, 20 \mathrm{mg}, 50 \mathrm{mg}$ and $100 \mathrm{mg}$ sustainedrelease capsules. † Includes $5 \mathrm{mg}, 10 \mathrm{mg}, 20 \mathrm{mg}, 40 \mathrm{mg}$ and $80 \mathrm{mg}$ controlled release tablets and $5 \mathrm{mg}, 10 \mathrm{mg}$, and $20 \mathrm{mg}$ capsules. $\ddagger$ Data obtained from the Drug Utilisation Sub-Committee of the Pharmaceutical Benefits Advisory Committee. 


\section{Indicators of harms associated with "other opioid"* and heroin use in Australia ${ }^{\dagger}$}

(A) Hospital separations for opioid poisoning

(B) Treatment episodes for problems related to morphine, oxycodone and heroin
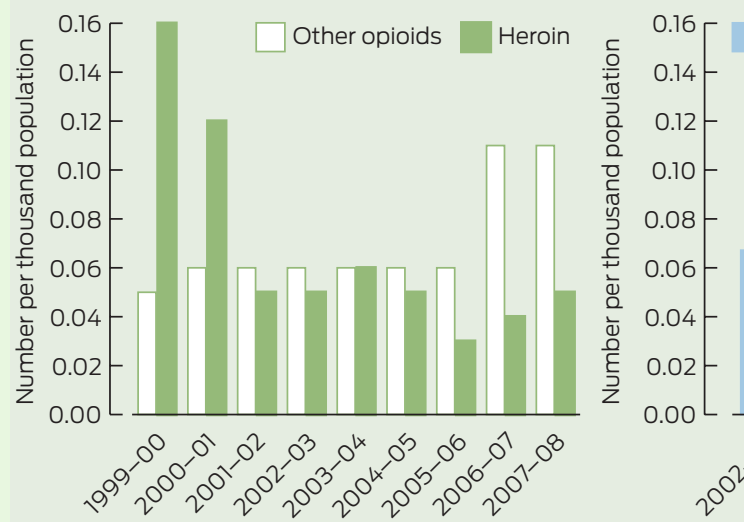

Morphine
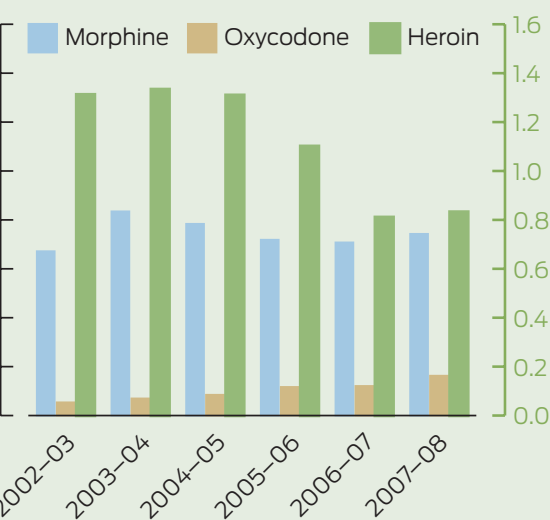

*Morphine, oxycodone, and codeine. † Data obtained from the Australian Institute of Health and Welfare's Alcohol and Other Drug Treatment Services National Minimum Dataset and National Hospital Morbidity Database.

3 All opioid-related mortality and oxycodone mortality for 2002-2008*†

Parameter

All opioid-related deaths ${ }^{\ddagger}$

Oxycodone deaths

Calculated defined daily doses of oxycodone (millions) $^{\xi}$

Oxycodone deaths per million defined daily doses

* Data from Degenhardt and Roxburgh. ${ }^{16}$ the National Coronial Information System, and the Drug Utilisation Sub-Committee of the Pharmaceutical Benefits Advisory Committee. $\uparrow 2001$ and 2009 figures have been omitted in the event that these cases are not complete. ‡Includes oxycodone deaths; changes in data collation render trends beyond 2005 not comparable. $\$$ These calculations relate to all oral oxycodone preparations that were dispensed on the Pharmaceutical Benefits Scheme.
2002200320042005200620072008

$\begin{array}{ccccccc}364 & 357 & 357 & 374 & & & \\ 31 & 46 & 48 & 59 & 61 & 94 & 59 \\ 4.26 & 5.74 & 7.59 & 9.20 & 11.09 & 13.33 & 15.6 \\ 7.3 & 8 & 6.3 & 6.4 & 5.5 & 7.1 & 3.8\end{array}$

re

$\bullet$

$P<0.001) ; 80+$ years, $12.61(95 \% \mathrm{CI}$, 9.12-16.11; $P<0.001)$. All trends were strongly linear $\left(\mathrm{R}^{2}\right.$ for linear trend, $\geqslant 0.91$, except the $40-49$-years age group $\left.\left[R^{2}=0.73\right]\right)$.

Analysis of prescriptions by dosage strength (data not shown) showed that the $15-30 \mathrm{mg}$ formulations accounted for the largest proportion $(34.5 \%)$ of all oral morphine prescriptions. This declined slightly but significantly between 2002-03 and 200708 (annual decline, $0.25 \%$; 95\% CI, $0.17 \%-0.34 \% ; P<0.001)$. The stronger formulations - 50-60 mg and $90 \mathrm{mg}$ and over (predominantly $100 \mathrm{mg}$ tablets) - accounted for relatively smaller proportions of all formulations $(21.4 \%$ and $19.5 \%$, respectively) in 2007-08. However, the market share of these stronger formulations relative to all morphine prescriptions increased between 2002-03 and 2007-08 (annual increase, $0.26 \%$ [95\% CI, $0.12 \%-$ $0.40 \% ; P=0.02]$ and $0.48 \%$ [95\% CI, $0.35 \%-0.61 \% ; P<0.001]$, respectively). Prescriptions for the $60 \mathrm{mg}$ and $100 \mathrm{mg}$ tablets were most com- mon among the 40-49-year age group, and have remained relatively stable (data not shown).

In contrast, oxycodone prescriptions in Australia increased markedly from 35.3 to 89.2 per 1000 population between 2002-03 and 2007-08, representing an increase of about $152 \%$. Significant linear increases over time are apparent across all age groups (Box 1B). Linear regression showed statistically significant $(P \leqslant 0.001)$ annual increases per 1000 population for each group of: 20-29 years, 1.64 (95\% CI, 1.27-2.00); 30-39 years, 4.55 (95\% CI, 4.19-4.92); 40-49 years, 8.59 (95\% CI, 8.28-8.90); 50-59 years, 11.14 (95\% CI, 10.58-11.70); 60-69 years, 19.02 (95\% CI, 17.04-21.00); 70-79 years, 33.23 (95\% CI, 30.73$35.72) ; 80+$ years, 59.17 (95\% CI, 54.66-63.68). All trends were strongly linear $\left(R^{2}\right.$ for linear trend, $\left.\geqslant 0.94\right)$.

Analysis of prescriptions by dosage strength shows that $5 \mathrm{mg}, 10 \mathrm{mg}$ and $20 \mathrm{mg}$ formulations accounted for the largest proportion of all oral oxycodone prescriptions $(30.2 \%, 21.6 \%$ and $19.6 \%$, respectively) in 2007-08 (data not shown). The proportion of $10 \mathrm{mg}$ formulations increased significantly from $16.1 \%$ in 2002-03 (annual increase, $1.08 \%$; 95\% CI, $0.75 \%-$ $1.41 \% ; P<0.001)$. The most potent formulation $(80 \mathrm{mg}$ ) accounted for the smallest proportion of prescriptions (6.3\% in 2007-08), and this has been stable across time. Age analysis shows that prescriptions for $80 \mathrm{mg}$ tablets were highest among the 40-49-years age group, and increased by about $25 \%$ in this group over time (data not shown).

\section{Hospital separations}

The number of hospital separations for poisoning with "other opioids" (morphine, oxycodone and codeine, but not heroin) was higher in 2007-08 (0.11 per 1000 population) than in 1999-00 (0.05 per 1000 population). Hospital separations almost doubled in 2006-07 (Box 2A).

\section{Outpatient treatment episodes}

Treatment episodes for problematic morphine use remained relatively stable during 2002-03 to 2007-08 (0.07 per 1000 population in 2007-08). Episodes for problematic oxycodone use doubled, from 0.01 per 1000 population in 2002-03 to 0.02 per 1000 population in 2007-08 (Box 2B).

\section{Oxycodone-related deaths}

There were 465 oxycodone-related deaths identified between 2001 and 2009. Box 3 shows deaths by year from 2002 to 2008, with the largest number occurring in 2007. Deaths adjusted for quantity of oxycodone prescribed each year fluctuated between 3.8 and 8 deaths per million defined daily doses (Box 3). Only 10\% of these deaths were due to oxycodone toxicity alone. Multiple drug toxicity was more predominant $(82 \%$ of deaths), with benzodiazepines and alcohol commonly implicated in these deaths. The remaining $8 \%$ were from other causes (eg, pneumonia or cardiac failure), with drug toxicity (including oxycodone toxicity) being a contributory cause (data not shown).

Median age at death related to oxycodone was 42 years (range, 15-86 years), with most deaths occurring among 40-49-year-olds (31\%), followed by $30-39$-year-olds (27\%). A quarter of decedents $(124 ; 27 \%)$ were 
4 Characteristics of oxycodone-related deaths, 2001 to 2009*

\begin{tabular}{lccc} 
Variable & Total & $\begin{array}{c}\text { Injecting drug } \\
\text { users }\end{array}$ & $\begin{array}{c}\text { Non-injecting drug } \\
\text { users }\end{array}$ \\
\hline All oxycodone-related deaths & 465 & 124 & 252 \\
Male & $263(57 \%)$ & $94(76 \%)^{\dagger}$ & $116(46 \%)$ \\
Mean age in years & $43.6(15$ to 86$)$ & 37.5 & $46^{\dagger}$ \\
Age group ${ }^{\ddagger}$ & & & \\
$20-29$ years & $60(13 \%)$ & $25(20 \%)$ & $25(10 \%)$ \\
$30-39$ years & $125(27 \%)$ & $48(39 \%)$ & $59(23 \%)$ \\
$40-49$ years & $145(31 \%)$ & $39(31 \%)$ & $75(30 \%)$ \\
$50-59$ years & $68(15 \%)$ & $11(9 \%)$ & $42(17 \%)$ \\
$\quad 60-69$ years & $42(9 \%)$ & -5 & $33(13 \%)$ \\
$70+$ years & $20(4 \%)$ & 0 & $14(6 \%)$ \\
Suicide & $127(27 \%)$ & $7(6 \%)$ & $89(35 \%)^{\dagger}$ \\
History of injecting drug use & $124(27 \%)$ & & $182(72 \%)^{\dagger}$ \\
History of chronic medical & $240(52 \%)$ & $43(35 \%)$ & $191(76 \%)^{\dagger}$ \\
condition and/or pain & $248(53 \%)$ & $44(35 \%)$ & \\
Oxycodone prescribed & $24 \%)$ &
\end{tabular}

* Data from the National Coronial Information System. $\dagger$ Significant at $P<0.001$. $\neq$ Deaths among those under 20 years of age not published to protect confidentiality. $\$$ Not published to protect confidentiality.

IDUs. In half of the cases of oxycodone-related death (53\%), it was recorded that oxycodone had been prescribed to the decedents, and half of the decedents (52\%) had a history of a chronic medical condition and/or pain. About a quarter of oxycodonerelated deaths $(27 \%)$ were recorded as suicides (Box 4).

IDUs were significantly more likely than non-IDUs to be male $(76 \% \mathrm{~V}$ 46\%; OR, 1.7; 95\% CI, 1.4-2.1), while non-IDUs were significantly older than IDUs $\left(46.0\right.$ years $\mathrm{v} 37.5 ; t_{(351)}=$ 7.3; $P<0.001)$, and significantly more likely than IDUs to have intentionally taken an overdose (35\% v 6\%; OR, 6.3; 95\% CI, 3.0-13.1). Non-IDUs were also significantly more likely than IDUs to have been prescribed oxycodone at the time of their death (76\% v 35\%; OR, 4.5; 95\% CI, 2.8-7.4) and to have a chronic medical condition (72\% v 35\%; OR, 3.5; 95\% CI, $2.4-5.2)$.

\section{Discussion}

This is the first Australian report to document oxycodone-related mortality at a national level, and it provides important clarification of prescription trends. There is increasing concern in Australia that problems related to oxycodone seen in the United States might be emerging here. Although there are lessons to be learned from the US experience, the prescription, use and diversion of morphine and oxycodone occurs within a different context in Australia. Opioid analgesic deaths, among which oxycodone is prevalent, ${ }^{11}$ now outnumber those for heroin and cocaine in the US. ${ }^{17}$ It is important to consider these issues in Australia with reference to the local evidence base.

Overall, the rate of morphine prescribing in Australia has declined across most age groups, with prescriptions remaining most common for people aged over 80 years. In contrast, oxycodone prescribing has increased markedly, particularly among older Australians (those aged 60 years and over), who most commonly receive low-dose formulations. Higher dose formulations of both morphine and oxycodone constituted a minority of overall prescriptions, and were most common among 4049-year-olds.

The recent increase in hospital separations for opioid poisoning in Australia is concerning, but we were unable to ascertain what proportion of this increase is attributable to oxycodone and morphine; or over-thecounter medications containing codeine. Treatment episodes for problematic use of morphine have remained relatively stable, while those for oxycodone have increased. However, numbers of treatment epi- sodes still remain much lower than those for heroin (for which there were 15571 in 2007-08). ${ }^{18}$

Oxycodone-related deaths have increased in number over the past 7 years, and were most prominent among 40-49-year-olds. Most of these deaths occurred among people who were not IDUs, had a chronic medical condition, and had been prescribed oxycodone. A quarter of decedents were IDUs, and about a third of this group also had a chronic medical condition. Oxycodonerelated deaths overall remain lower in number than heroin-related deaths. ${ }^{19}$ Once these deaths are adjusted for the quantity of oxycodone prescribed (per million defined daily doses), the trend shows relatively low mortality. The contribution of prescription morphine formulations to opioid mortality in Australia remains largely unknown.

Our findings have important implications for ongoing monitoring. Oxycodone prescriptions are clearly increasing in Australia, but the increase may be consistent with appropriate treatment of pain among older Australians. Developing a national real-time prescription system, accessible by medical practitioners and pharmacists, including diagnosis information, would provide important context in understanding the extent of prescription and use of pharmaceutical opioids while improving patient care. It may also reduce the potential for non-medical use and diversion of these drugs, ${ }^{4}$ which has been found to be linked with increased rates of mortality in North America. ${ }^{12,20}$

Our findings have implications for treatment and policy responses aimed at minimising non-medical use and diversion of, and harms related to, opioid analgesics. As problems with the use of these drugs increase, making options for treating dependence more available is crucial, as is developing strategies to enhance the engagement of non-IDU populations in these services. ${ }^{21}$ There is a continued need for comprehensive training of general practitioners in assessing and prescribing opioids for patients with chronic non-malignant pain, including ongoing monitoring and review of medication, particularly 
given the complexity of these patients' presentations. ${ }^{7}$ Opioid prescribing should not be the first-line response to pain management, particularly given that long-term use of opioids may: (i) lower the threshold to pain; and (ii) be ineffective in targeting pain long-term. ${ }^{22}$

Evidence suggests that there is a large psychological component to the experience of chronic pain, ${ }^{23}$ and research investigating the efficacy of non-pharmacological interventions for pain management is needed. Given that a minority of oxycodonerelated deaths are occurring among IDUs, messages about the harms associated with these drugs need to reach a broader audience. Greater focus on policy monitoring, and on treatment responses among non-IDU populations, is therefore essential. Finally, given the prevalence of suicide among oxycodone-related deaths, these risks need to be considered by GPs during their evaluation of patients for prescription of opioid analgesics, and during ongoing patient monitoring.

Our findings lead us to make the following key recommendations:

- A national online prescription system should be developed and training and ongoing support should be provided for health practitioners in prescribing opioid analgesics, to reduce diversion.

- The efficacy of non-pharmacological responses to pain management should be investigated.

- GPs should monitor their patients' medication use and mental health issues to minimise the risk of intentional overdose among patients with chronic pain

Our study has certain limitations that must be acknowledged. The NHMD does not differentiate between morphine, oxycodone or codeine poisonings, and some case reports suggest that the increase in "other opioid" poisonings may be attributable to over-the-counter codeine preparations. ${ }^{24}$ Systematic recording of the morbidity and mortality associated with codeine preparations would be pertinent, particularly given that these are not regulated in Australia.

Further, the NCIS may yield an underestimate of deaths related to oxycodone, as implicated drugs may have been miscoded or misspelt. However, data administrators undertake quality assurance work regularly to minimise the impact of errors. We undertook a range of search strategies for this report in an effort to maximise the numbers of records returned.

In conclusion, the available data suggest that prescriptions for oxycodone are increasing in Australia, but these are predominantly for low-dose formulations, and for older patients. Part of the increase may reflect appropriate prescribing for pain. Oxycodone-related deaths in Australia do not appear to have reached proportions seen in the US. Access to effective pain relief is an important human right, which should not be overlooked in the debate about policy responses regarding the prescribing of these drugs in Australia.

Acknowledgements: We acknowledge the Australian Institute of Health and Welfare for providing the NHMD and the AODTS-NMDS data, and the state and territory health departments for agreeing to our access to these data. We also acknowledge the Victorian Institute of Forensic Medicine for access to the NCIS. Finally, we acknowledge the Drug Utilisation Sub-Committee Secretariat, Australian Government Department of Health and Ageing for providing the prescription data. Particular thanks to Maxine Robinson and Vanna Mabbott for help and advice in calculating the daily defined doses per million for oxycodone prescriptions.

Competing interests: Briony Larance has received untied educational grants from Reckitt Benckiser for two studies. Reckitt Benckiser has no knowledge of, or role in, the development or writing of this article.

Received 14 Dec 2010, accepted 29 Jun 2011.

1 International Narcotics Control Board. Narcotic drugs: estimated world requirements for 2010 Statistics for 2008. New York: United Nations, 2009.

2 Berbatis CG, Sunderland VB, Bulsara M, Lintzeris N. Trends in licit opioid use in Australia, 19841998: comparative analysis of international and jurisdictional data. Med J Aust 2000; 173: 524527.

3 Bell JR. Australian trends in opioid prescribing fo chronic non-cancer pain, 1986 to 1996. Med 」 Aust 1997; 167: 26-29.

4 Royal Australasian College of Physicians. Prescription opioid policy: improving management of chronic non-malignant pain and prevention of problems associated with precription opioid use. Sydney: RACP, 2009.

5 Cousins MJ, Brennan F, Carr DB. Pain relief: a universal human right. Pain 2004; 112: 1-4.

6 World Health Organization. Cancer pain relief with a guide to opioid availability. 2nd ed. Geneva:WHO, 1996.
7 Trescot AM, Helm S, Hansen H, et al. Opioids in the management of chronic non-cancer pain: an update of American Society of the Interventional Pain Physicians' (ASIPP) Guidelines. Pain Physician 2008; 11: S5-S62.

8 Kumar N. WHO Normative guidelines on pain management. Geneva: World Health Organization, 2007.

9 Manchikanti L, Giordano J, Boswell MV, et al Psychological factors as predictors of opioid abuse and illicit drug use in chronic pain patients. J Opioid Manag 2007; 3: 89-100.

10 Degenhardt L, Black E, Breen C, et al. Trends in morphine prescriptions, illicit morphine use and associated harms among regular injecting drug users in Australia. Drug Alcohol Rev 2006; 25 : 403-412.

11 Moore TJ, Cohen MR, Furberg CD. Serious Adverse Drug Events Reported to the Food and Drug Administration, 1998-2005. Arch Intern Med 2007; 167: 1752-1759.

12 Hall AJ, Logan JE, Robin L, et al. Patterns of abuse among unintentional pharmaceutical overdose fatalities. JAMA 2008; 300: 2613-2620.

13 World Health Organization. The ICD-10 classification of mental and behavioural disorders - diagnostic criteria for research. Geneva: WHO, 1993.

14 Drummer $\mathrm{OH}$. Recent trends in narcotic deaths. Ther Drug Monit 2005; 27: 738-740.

15 Strang J, Hall WD, Hickman M, Bird S. Impact of supervision of methadone consumption on deaths related to methadone overdose (19932008): analyses using OD4 index in England and Scotland. BMJ 2010; 341: 4851-4857.

16 Degenhardt L, Roxburgh A. Accidental druginduced deaths due to opioids in Australia, 2005. Sydney: National Drug and Alcohol Research Centre, 2007

17 Paulozzi LJ, Xi Y. Recent changes in drug poisoning mortality in the United States by urban-rural status and by drug type. Pharmacoepidemiol Drug Saf 2009; 17: 997-1005.

18 Australian Institute of Health and Welfare. Alcohol and other drug treatment services in Australia 2007-08: report on the National Minimum Data Set. Canberra: AlHW, 2009. (AIHW Cat. No. HSE 73.) http:// www.aihw.gov.au/publication-detail/?id= 6442468294\&tab=2 (accessed Jul 2011).

19 Roxburgh A, Burns L. Drug-induced deaths in Australia 2006. Sydney: National Drug and Alcohol Research Centre, University of New South Wales, 2009

20 Dhalla IA, Mamdani, MM, Sivilotti, MLA, et al. Prescribing of opioid analgesics and related mortality before and after the introduction of long-acting oxycodone. CMAJ 2009; 181: 891896.

21 Nielsen S, Bruno R, Lintzeris N, et al. Pharmaceutical opioid analgesic and heroin depdendence: how do treatment-seeking clients differ in Australia? Drug Alcohol Rev 2011; 30: 291299.

22 Kalso E, Edwards JE, Moore RA, McQuay HJ. Opioids in chronic non-cancer pain: systematic review of efficacy and safety. Pain 2004; 112: 372380.

23 TurkDC, Okifuji A. Psychological factors in chronic pain: evolution and revolution. J Consult Clin Psychol 2002; 70: 678-690.

24 Frei MY, Neilson S, Dobbin MD, Tobin CL. Serious morbidity associated with misuse of over-thecounter codeine-ibuprofen analgesics: a series of 27 cases. Med J Aust 2010; 193: 294-296. 